\title{
Degradabilidade in situ dos componentes do feno de capim Andropogon Gayanus colhido em diferentes idades
}

\author{
Cavalcanti, André Cayôo, ${ }^{1, *}$ Eloísa de Oliveira Simões Saliba²; Lúcio Carlos Gonçalves²; \\ Iran Borges ${ }^{2 ;}$ Norberto Mario Rodriguez ${ }^{2}$ \\ 1Universidade Federal do Espírito Santo, Centro Universitário Norte do Espírito Santo. Rodovia BR - 101 \\ Norte km 60 Litorâneo 29932540 - São Mateus, ES - Brasil; ²Universidade Federal de Minas Gerais, \\ Departamento de Zootecnia, Escola de Veterinária. São Francisco Belo Horizonte, MG - Brasil. Caixa postal \\ 567; * andrecavalcanti40@yahoo.com.br
}

Cavalcanti, André Cayô; Eloísa de Oliveira Simões Saliba; Lúcio Carlos Gonçalves; Iran Borges; Norberto Mario Rodriguez (2020). Degradabilidade in situ dos componentes do feno de capim Andropogon Gayanus colhido em diferentes idades. Rev. Fac. Agron. Vol 119 (2): 1-10. https://doi.org/10.24215/16699513e061

Objetivou-se com este trabalho determinar a degradabilidade ruminal e os parâmetros da cinética de degradação da matéria seca, matéria orgânica, proteína bruta e frações fibrosas dos fenos de Andropogon gayanus produzidos a partir de 56, 84 e 112 dias de idade. O delineamento estatístico utilizado foi o de blocos ao acaso em esquema de parcelas subdivididas, sendo cinco animais utilizados como blocos, as três idades como parcelas e sete tempos $(0,3,6,12,24,48$ e 96 horas) de incubação como subparcelas. As médias foram comparadas pelo teste SNK ao nível de 5\% de significância. O desaparecimento ruminal médio da matéria seca, matéria orgânica, proteína bruta e das porções fibrosas, após 96 horas de incubação ruminal, foram maiores $(P<0,05)$ para o feno colhido aos 56 dias, quando comparado aos fenos colhidos aos 84 e 112 dias de idade. O maior potencial e taxa de degradação ruminal dos nutrientes indicam que melhores fenos de $A$. gayanus são obtidos aos 56 dias de idade.

Palavras- chave: conservação; gramínea; ruminantes

Cavalcanti, André Cayô; Eloísa de Oliveira Simões Saliba; Lúcio Carlos Gonçalves; Iran Borges; Norberto Mario Rodriguez (2020). Evaluation of hays produced with Andropogon Gayanus at different ages using in situ degradability technique. Rev. Fac. Agron. Vol 119 (2): 1-10. https://doi.org/10.24215/16699513e061

In this study were evaluated Andropogon gayanus hays produced at different ages of growth (56, 84 and 112 days) to assay in situ dry matter (DM), organic matter (OM), crude protein (CP), and fiber fractions degradability. The statistical design was randomized blocks with split plots. The ages of growth were parcels and degradation time $(0,3,6,12,24,48$ and 96 hours) were subparcels with five repetition by treatment (blocks). The different ages showed the same degradation kinetic behavior. A. gayanus hays produced with plant between 56 days are different from the 84 and 112 days of growth and had higher degradation for DM,OM,CP, NDF and ADF. The observed results indicated that the best $A$. gayanus hays are obtained from plants cut in between 56 days.

Key words: conservation; gramínea; ruminant

https://revistas.unlp.edu.ar/revagro

Recibido: 26/03/2020

Aceptado: $27 / 05 / 2020$

Disponible on line: $07 / 12 / 2020$

ISSN 0041-8676 - ISSN (on line) 1669-9513, Facultad de Ciencias Agrarias y Forestales, UNLP, Argentina. 


\section{INTRODUÇÃO}

As pastagens constituem a base da dieta dos ruminantes na grande maioria dos sistemas de produção brasileiros, devido às condições edafoclimáticas do nosso país favorecerem a produção de forrageiras tropicais. Entre as forrageiras com maior área cultivada destacam-se as espécies dos gêneros Brachiaria, Panicum, Pennisetum, Cynodon e Andropogon. O capim Andropogon (Andropogon gayanus) se destaca por sua alta produção de biomassa, capacidade de tolerar solos ácidos com baixa fertilidade e períodos de seca prolongados. Por esses motivos, este capim é considerado uma das gramíneas mais adaptadas a algumas regiões brasileiras sendo, atualmente, amplamente utilizado como pastagem cultivada, principalmente nas áreas de Cerrado (Cavalcanti et al., 2016; 2018).

O capim Andropogon concentra a maior parte da produção de matéria seca durante a estação quente e chuvosa do ano. Desse modo, em certas situações, adota-se a prática de conservar parte desta produção, para posteriormente ser utilizada na estação seca, com o intuito de manter uniforme a disponibilidade de volumoso aos animais durante todo o ano (Cavalcanti et al., 2019; Ribeiro Júnior et al., 2014; Moreira et al., 2013). Baseado neste fato, uma alternativa recomendada neste tipo de situação tem sido a conservação desta forrageira na forma de feno.

A avaliação do valor nutricional das forrageiras em função da idade pode ser realizada através de diferentes técnicas, sendo o método in vivo considerado o mais preciso. Por outro lado, a técnica in situ possui a vantagem de ser menos trabalhosa e onerosa, além de utilizar um menor volume de amostra e ser capaz de descrever a degradabilidade ruminal do alimento. Esta metodologia baseia-se no uso de animais fistulados no rúmen e nas medidas do desaparecimento de frações das amostras acondicionadas em sacos mantidos em incubação ruminal por períodos pré-estabelecidos, apresentando altas correlações com os resultados obtidos in vivo (Jung, 2011; Rodrigues et al., 2011; Sousa et al., 2011).

Dessa forma objetivou - se com este experimento avaliar fenos de Andropogon gayanus colhidos em diferentes idades de crescimento (56, 84 e 112 dias) pela técnica de degradabilidade in situ.

\section{MATERIAL E MÉTODOS}

O feno foi produzido em uma fazenda localizada no município de Lagoa Santa - Minas Gerais, sendo utilizada uma área de capim Andropogon gayanus já estabelecida. Na análise de solo observaram-se as seguintes características: $\mathrm{pH} 5,3, \mathrm{Al}^{3+} \quad 0,6$ cmol.carga/ $/ \mathrm{dm}^{3}, \mathrm{P} 1,5 \mathrm{mg} / \mathrm{dm}^{3}, \mathrm{~K} 183 \mathrm{mg} / \mathrm{dm}^{3}$, índice de saturação de bases de $39 \%$ e classificação de textura franco argilosa. Com base na análise de solo, no início do período chuvoso, procedeu-se a correção da acidez com a aplicação de $2000 \mathrm{~kg} / \mathrm{ha}$ de calcário dolomítico. Quarenta e cinco dias depois, foi realizada a uniformização da área experimental, a $20 \mathrm{~cm}$ do solo com o uso de roçadeira movida pela tomada de força do trator, e a adubação. Para adubação de cobertura foram utilizados $250 \mathrm{~kg} / \mathrm{ha}$ de 08-24-12 e $100 \mathrm{~kg} / \mathrm{ha}$ de 30-00-20 (N:P:K). O capim foi submetido ao corte em três épocas ( 3 tratamentos), nas seguintes idades de crescimento: 56, 84 e 112 dias. O primeiro corte foi realizado dia 27 de janeiro de 2007 e os demais a cada 28 dias.

A confecção dos fenos foi realizada na Escola de Veterinária da Universidade Federal de Minas Gerais, onde a forragem cortada anteriormente foi colocada em bandejas de ferro de $1 \mathrm{~m}^{2}(1 \times 1 \mathrm{~m})$, em camadas de 5 $\mathrm{cm}$ e expostas ao sol, sendo reviradas quatro vezes ao dia. Caso não dessem ponto de feno, as bandejas eram recolhidas e colocadas em galpão, para evitar 0 orvalho, e no dia seguinte eram expostas novamente ao sol. O ponto de feno era observado quando ao torcer um molho de folhas e hastes, apenas algumas se rompiam.

As amostras com feno do capim $A$. gayanus foram présecadas em estufa de ventilação forçada a $55^{\circ} \mathrm{C}$ por 72 horas. Posteriormente o material foi moído em moinho com peneira de 5,0 mm e usado para o estudo in situ.

Foram utilizadas cinco novilhas mestiças fistuladas no rúmen, com peso aproximado de $400 \mathrm{~kg}$, sendo estas previamente vermifugadas. As novilhas foram mantidas em piquetes, onde tiveram livre acesso à água e sal mineral. A limpeza dos cochos foi realizada diariamente juntamente com a inspeção dos bebedouros. A dieta dos animais era composta por pasto de Brachiaria brizantha cv. Marandu mais $2 \mathrm{~kg}$ de concentrado (com $18 \%$ de PB) por animal.

Os sacos de náilon utilizados no ensaio apresentavam poros de 50 micrômetros $(\mu \mathrm{m})$ e dimensões de 10 por $20 \mathrm{~cm}$. Eles foram secos a $55^{\circ} \mathrm{C}$ por 24 horas e tiveram seus pesos registrados. Posteriormente, foram cheios com $5 \mathrm{~g}$ de amostra por tratamento, previamente moída a 5,0 mm. Os sacos com as amostras foram atados por presilhas plásticas a um aro metálico, respeitando-se a relação próxima de $16 \mathrm{mg}$ de amostra por $\mathrm{cm}^{2}$ de área útil de saco de náilon. Este aro foi atado a uma presilha de contenção tipo chaveiro, que manteve três aros, e consequentemente, três sacos. Foi utilizada uma corrente com um cilindro de ferro (aproximadamente 150 gramas) funcionando como âncora. Foram utlizados três repetições por cada tratamento de forragem.

Os tempos de incubação foram de 3, 6, 12, 24, 48 e 96 horas. Foram incubados três sacos por tipo de forragem (56, 84 e 112 dias de idade) para cada um dos tempos. Todos os tratamentos foram incubados ao mesmo tempo. Imediatamente depois de retirados do rúmen, os sacos foram imersos em água fria e posteriormente lavados, manualmente, em água corrente a temperatura ambiente até que a água ficasse límpida. Após a lavagem, os sacos foram colocados em bandejas e armazenados em um freezer $\left(-15^{\circ} \mathrm{C}\right)$ até serem processados. Posteriormente todo o material foi levado ao Laboratório de Nutrição Animal da Escola de Veterinária da UFMG e secos em estufa a 55ㄷ com ventilação forçada por 72 horas, sendo então 
transferidos para um dessecador durante 30 minutos sendo então pesados. Descontando-se o peso do saco vazio e limpo, foi determinado o desaparecimento da matéria pré-seca no rúmen. Após esse procedimento o material restante nos sacos, de mesmo animal, tratamento e período de incubação, foram transformados em um pool homogêneo, para posterior moagem a $1,0 \mathrm{~mm}$ e armazenados em recipientes plásticos vedados.

Os valores para o tempo zero foram determinados a partir da lavagem manual dos sacos de náilon por 20 minutos em água de torneira. Estes foram fechados e tiveram a mesma quantidade de amostra utilizada para os demais horários de incubação. Após a lavagem os sacos foram secos em estufa a $55^{\circ} \mathrm{C}$ com ventilação forçada por 72 horas, sendo então transferidos para um dessecador durante 30 minutos e pesados. Dessa forma, foi quantificada a fração solúvel de cada tratamento. Neste caso foram realizadas 5 réplicas por tratamento.

Nos resíduos de incubação ruminal e do tempo zero, bem como no material incubado, foram analisados os valores de matéria seca em estufa a $105^{\circ} \mathrm{C}$, matéria mineral em mufla a $600^{\circ} \mathrm{C}$, proteína bruta, fibra em detergente neutro (FDN) e fibra em detergente ácido (FDA) pelo método sequencial no aparelho Fiber analyser ANKOM ${ }^{220}$ (Detmann et al., 2012).

Os parâmetros de degradabilidade in situ foram obtidos pelo procedimento de MARQUARDT do programa estatístico computacional SAEG (Euclydes, 2005).

Os dados das degradações dos constituintes bromatológicos dos fenos foram submetidos a análise de regressão, na qual foram regredidos ao modelo assintótico de primeira ordem proposto por Ørskov e Mcdonald (1979):

$$
D P=a+b\left(1-\exp ^{-c t}\right)
$$

Em que:

DP: representa a degradabilidade ruminal potencial dos alimentos;

a: a fração solúvel;

b: a fração potencialmente degradável da fração

insolúvel que seria degradada

a uma taxa "c";

c: a taxa de degradação da fração "b";

t: o tempo de incubação em horas.

A fração considerada indegradável (I) foi calculada da seguinte forma:

$$
I=(100-(a+b))
$$

Em que:

a e b são os mesmos parâmetros citados acima.

Para calcular a degradabilidade efetiva (DE), foi utilizada a equação também proposta por Ørskov e Mcdonald (1979):

Em que:

$$
\mathrm{DE}=\mathrm{a}+[(\mathrm{bc}) /(\mathrm{c}+\mathrm{K})]
$$

a, b e c são os mesmos parâmetros citados acima;

$\mathrm{K}$ : valor correspondente a taxa de passagem. (Neste trabalho foi considerado taxa de passagem (K) de $2 \% /$ hora).

Para a análise dos dados de desaparecimento dos componentes nutricionais das amostras foi empregado um delineamento experimental de blocos ao acaso em esquema de parcelas subdivididas, tendo os animais como blocos, as idades das plantas como parcelas e os tempos de incubação como subparcelas.

As análises das médias foram comparadas empregando-se o teste Studant-Newman-Keuls (SNK), a $5 \%$ de probabilidade.

\section{RESULTADOS}

A composição bromatológica do feno de capim Andropogon gayanus colhido em diferentes idades de crescimento (56, 84 e 112 dias) encontra-se na Tabela 1.

Tabela 1. Valor nutritivo do feno de capim Andropogon gayanus colhido em diferentes idades de

\begin{tabular}{|c|c|c|c|}
\hline & \multicolumn{3}{|c|}{ Idade (dias) } \\
\hline & 56 & 84 & 112 \\
\hline Matéria seca (\%) & 81,69 & 85,67 & 87,55 \\
\hline Proteína Bruta (\%MS) & 7,27 & 6,12 & 4,71 \\
\hline Fibra em detergente neutro (\%MS) & 71,10 & 73,62 & 75,54 \\
\hline Fibra em detergente ácido (\%MS) & 42,15 & 43,32 & 45,61 \\
\hline Lignina (\%MS) & 5,25 & 6,08 & 6,23 \\
\hline $\mathrm{NIDN}^{1}(\% \mathrm{~N}$ total $)$ & 30,40 & 41,12 & 42,12 \\
\hline $\mathrm{NIDA}^{2} /(\% \mathrm{~N}$ total $)$ & 17,01 & 20,18 & 24,70 \\
\hline Digestibilidade in vitro da MS (\%) & 61,93 & 56,34 & 48,06 \\
\hline Energia Bruta (Mcal/kg) & 4,100 & 4,194 & 4,305 \\
\hline
\end{tabular}
crescimento. ${ }^{1}$ Nitrogênio insolúvel em detergente neutro; ${ }^{2}$ Nitrogênio insolúvel em detergente ácido.

Observou-se que no período inicial de incubação ruminal de 0 e 3 horas os fenos colhidos nas três diferentes idades (56, 84 e 112 dias) apresentaram valores semelhantes $(p>0,05)$ de desaparecimento ruminal da matéria seca (DRMS). A partir do tempo de incubação de 6 até 96 horas, o feno colhido aos 56 dias apresentou valores de DRMS superiores $(p<0,05)$ aos encontrados nos fenos colhidos aos 84 e 112 dias, que foram semelhantes entre si (Tabela 2).

Observa-se na Tabela 3 que os valores médios da degradabilidade ruminal (fração a, b, c a+b, I) e da degradabilidade efetiva da matéria seca (DEMS) foram próximos para os fenos colhidos nas três diferentes idades de crescimento.

Verifica-se que no período inicial de incubação ruminal de 0 e 3 horas (Tabela 4), os fenos colhidos nas três diferentes idades (56, 84 e 112 dias) apresentam valores semelhantes $(p>0,05)$ de desaparecimento ruminal da matéria orgânica (DRMO). A partir do tempo de incubação de 6 até 96 horas, o feno colhido aos 56 dias apresentou valores de DRMO superiores $(p<0,05)$ 
aos encontrados para os fenos colhidos aos 84 e 112 dias, que foram semelhantes entre si.

Tabela 2. Desaparecimento ruminal médio (\%) da matéria seca dos fenos do capim Andropogon gayanus colhido aos 56, 84 e 112 dias de crescimento. Médias seguidas por letras minúsculas na mesma linha diferem estatisticamente entre si pelo teste SNK $(P<0,05)$. CV (coeficiente de variação): $4,5 \%$

\begin{tabular}{cccc}
\hline \multirow{2}{*}{$\begin{array}{c}\text { Tempo } \\
\text { (horas) }\end{array}$} & \multicolumn{3}{c}{ Idade de Corte } \\
\cline { 2 - 4 } & $\mathbf{5 6}$ dias & $\mathbf{8 4}$ dias & $\mathbf{1 1 2}$ dias \\
\hline 00 & $17,5^{\mathrm{a}}$ & $19,4^{\mathrm{a}}$ & $19,0^{\mathrm{a}}$ \\
03 & $24,9^{\mathrm{a}}$ & $21,4^{\mathrm{a}}$ & $20,3^{\mathrm{a}}$ \\
06 & $31,8^{\mathrm{a}}$ & $26,5^{\mathrm{b}}$ & $26,7^{\mathrm{b}}$ \\
12 & $45,2^{\mathrm{a}}$ & $37,5^{\mathrm{b}}$ & $35,6^{\mathrm{b}}$ \\
24 & $54,2^{\mathrm{a}}$ & $48,9^{\mathrm{b}}$ & $46,8^{\mathrm{b}}$ \\
48 & $69,3^{\mathrm{a}}$ & $59,2^{\mathrm{b}}$ & $58,7^{\mathrm{b}}$ \\
96 & $74,0^{\mathrm{a}}$ & $69,4^{\mathrm{b}}$ & $68,4^{\mathrm{b}}$ \\
\hline
\end{tabular}

Tabela 3. Valores médios de degradabilidade ruminal e degradabilidade efetiva da matéria seca dos fenos do capim Andropogon gayanus colhido aos 56, 84 e 112 dias de idade. Equações geradas pelo modelo Ørskov e McDonald (1979): ${ }^{1} D P=19,9+55,5$ (1 - exp $-(0,0410 \times t)) ;{ }^{2} D P=21,0+52,4(1-\exp -(0,0350 \times t)) ;{ }^{3} D P$ $=21,9+49,0(1-\exp -(0,0310 \times t))$. Legenda: $a=$ fração rapidamente degradável, $b=$ fração potencialmente degradável e $c=$ taxa constante de degradação da fração $b, I$ = fração indegradável e DEMS 2,0\%/h = degradabilidade efetiva da matéria seca nas taxas de passagem ruminal de $2 \% /$ hora.

\begin{tabular}{lccc}
\hline Parâmetros & \multicolumn{3}{c}{ Idade de Corte } \\
\cline { 2 - 4 } & $\mathbf{5 6}$ dias $^{\mathbf{1}}$ & $\mathbf{8 4}$ dias $^{2}$ & $\mathbf{1 1 2}$ dias $^{\mathbf{3}}$ \\
\hline a (\%) & 19,9 & 21,0 & 21,9 \\
b (\%) & 55,5 & 52,4 & 49,0 \\
c (\%/h) & 4,10 & 3,50 & 3,10 \\
a+b (\%) & 75,4 & 73,4 & 70,9 \\
I (\%) & 24,6 & 26,6 & 29,1 \\
DEMS 2,0\%/h (\%) & 57,2 & 54,3 & 51,7 \\
\hline
\end{tabular}

Para o tempo de incubação de 96 horas houve uma variação de 73,3 a $66,4 \%$, reduzindo-se com o avançar da idade, ocorrendo efeito da idade da forrageira sobre a DRMO (Tabela 4).

Observa-se na Tabela 5 que os valores médios da degradabilidade ruminal (fração a, b, c a+b, I) e da degradabilidade efetiva da matéria orgânica (DEMO) foram próximos para os fenos colhidos nas três diferentes idades de crescimento.
Tabela 4. Desaparecimento ruminal médio (\%) da matéria orgânica dos fenos do capim Andropogon gayanus colhido aos 56, 84 e 112 dias de crescimento. Médias seguidas por letras minúsculas na mesma linha diferem estatisticamente entre si pelo teste SNK $(P<0,05)$. CV (coeficiente de variação): $4,1 \%$

\begin{tabular}{cccc}
\hline \multirow{2}{*}{$\begin{array}{c}\text { Tempo } \\
\text { (horas) }\end{array}$} & \multicolumn{3}{c}{ Idade de Corte } \\
\cline { 2 - 4 } & $\mathbf{5 6}$ dias & $\mathbf{8 4}$ dias & $\mathbf{1 1 2}$ dias \\
\hline 00 & $15,8^{\mathrm{a}}$ & $17,0^{\mathrm{a}}$ & $17,9^{\mathrm{a}}$ \\
03 & $23,9^{\mathrm{a}}$ & $20,5^{\mathrm{a}}$ & $19,3^{\mathrm{a}}$ \\
06 & $27,5^{\mathrm{a}}$ & $22,2^{\mathrm{b}}$ & $22,7^{\mathrm{b}}$ \\
12 & $41,8^{\mathrm{a}}$ & $34,2^{\mathrm{b}}$ & $31,9^{\mathrm{b}}$ \\
24 & $51,3^{\mathrm{a}}$ & $46,1^{\mathrm{b}}$ & $44,0^{\mathrm{b}}$ \\
48 & $67,2^{\mathrm{a}}$ & $56,7^{\mathrm{b}}$ & $56,2^{\mathrm{b}}$ \\
96 & $73,3^{\mathrm{a}}$ & $67,4^{\mathrm{b}}$ & $66,4^{\mathrm{b}}$ \\
\hline
\end{tabular}

Tabela 5. Valores médios de degradabilidade ruminal e degradabilidade efetiva da matéria orgânica dos fenos do capim Andropogon gayanus colhido aos 56, 84 e 112 dias de idade. Equações geradas pelo modelo Ørskov e McDonald (1979): ${ }^{1} D P=16,9+58,2(1-\exp -(0,0390 \times t)) ;{ }^{2} D P=18,2+$ $54,6\left(1-\exp ^{-(0,0310 \times t)}\right) ;{ }^{3} D P=18,5+51,4\left(1-\exp ^{-}\right.$ $(0,0290 \times$ t $)$ ). Legenda: $a=$ fração rapidamente degradável, $b=$ fração potencialmente degradável e $c=$ taxa constante de degradação da fração $b, I=$ fração indegradável e DEMO 2,0\%/h = degradabilidade efetiva da matéria orgânica nas taxas de passagem ruminal de $2 \% / h o r a$

\begin{tabular}{lccc}
\hline Parâmetros & \multicolumn{3}{c}{ Idade de Corte } \\
\cline { 2 - 4 } & $\mathbf{5 6}$ dias $^{1}$ & $\begin{array}{c}\mathbf{8 4} \\
\text { dias }^{\mathbf{2}}\end{array}$ & $\begin{array}{c}\mathbf{1 1 2} \\
\text { dias }^{3}\end{array}$ \\
\hline a (\%) & 16,9 & 18,2 & 18,5 \\
b (\%) & 58,2 & 54,6 & 51,4 \\
c (\%/h) & 3,90 & 3,10 & 2,90 \\
a+b (\%) & 75,1 & 72,8 & 69,9 \\
I (\%) & 24,9 & 27,2 & 30,1 \\
DEMO 2,0\%/h (\%) & 55,4 & 51,4 & 48,9 \\
\hline
\end{tabular}

O desaparecimento ruminal da proteína bruta (DRPB) foi maior $(p<0,05)$ para o feno colhido aos 56 dias de crescimento em comparação aos colhidos com 84 e 112 dias, que foram semelhantes entre si $(p>0,05)$, exceto nos tempos de 24 e 48 horas (Tabela 6).

Verifica-se na Tabela 7 que os valores médios da degradabilidade ruminal (fração a, b, c a+b, I) e da degradabilidade efetiva da proteína bruta (DEPB) foram próximos para os fenos colhidos nas três diferentes idades de crescimento. 
Tabela 6. Desaparecimento ruminal médio (\%) da proteína bruta dos fenos do capim Andropogon gayanus colhido aos 56, 84 e 112 dias de crescimento. Médias seguidas por letras minúsculas na mesma linha diferem estatisticamente entre si pelo teste $S N K(P<0,05)$. CV (coeficiente de variação): $7,1 \%$

\begin{tabular}{cccc}
\hline \multirow{2}{*}{$\begin{array}{c}\text { Tempo } \\
\text { (horas) }\end{array}$} & \multicolumn{3}{c}{ Idade de Corte } \\
\cline { 2 - 4 } & $\mathbf{5 6}$ dias & $\mathbf{8 4}$ dias & $\mathbf{1 1 2}$ dias \\
\hline 00 & $32,7^{\mathrm{a}}$ & $22,1^{\mathrm{b}}$ & $21,7^{\mathrm{b}}$ \\
03 & $38,1^{\mathrm{a}}$ & $30,5^{\mathrm{b}}$ & $27,4^{\mathrm{b}}$ \\
06 & $46,9^{\mathrm{a}}$ & $35,3^{\mathrm{b}}$ & $34,0^{\mathrm{b}}$ \\
12 & $55,1^{\mathrm{a}}$ & $40,0^{\mathrm{b}}$ & $39,5^{\mathrm{b}}$ \\
24 & $63,8^{\mathrm{a}}$ & $54,7^{\mathrm{b}}$ & $44,6^{\mathrm{c}}$ \\
48 & $78,7^{\mathrm{a}}$ & $63,9^{\mathrm{b}}$ & $52,8^{\mathrm{c}}$ \\
96 & $83,5^{\mathrm{a}}$ & $70,7^{\mathrm{b}}$ & $65,7^{\mathrm{b}}$ \\
\hline
\end{tabular}

Tabela 7. Valores médios de degradabilidade ruminal e degradabilidade efetiva da proteína bruta dos fenos do capim Andropogon gayanus colhido aos 56, 84 e 112 dias de idade. Equações geradas pelo modelo Ørskov e McDonald (1979): ${ }^{1} D P=34,9+52,2\left(1-\exp ^{-(0,0379 \times t)}\right)$; ${ }^{2} D P=23,2+50,6(1-\exp -(0,0321 x t)) ;{ }^{3} D P=22,5+46,4$ $(1-\exp -(0,0239 \times t))$. Legenda: $a=$ fração rapidamente degradável, $b=$ fração potencialmente degradável e $c=$ taxa constante de degradação da fração $b, I=$ fração indegradável e DEPB 2,0\%/h = degradabilidade efetiva da proteína bruta nas taxas de passagem ruminal de $2 \% / h o r a$.

\begin{tabular}{lccc}
\hline Parâmetros & \multicolumn{3}{c}{ Idade de Corte } \\
\cline { 2 - 4 } & 56 dias & $\mathbf{8 4}$ dias $^{\mathbf{2}}$ & $\mathbf{1 1 2}$ dias $^{\mathbf{3}}$ \\
\hline a (\%) & 34,9 & 23,2 & 22,5 \\
b (\%) & 52,2 & 50,6 & 46,4 \\
c (\%/h) & 3,79 & 3,21 & 2,39 \\
a+b (\%) & 87,1 & 73,8 & 68,9 \\
I (\%) & 12,9 & 26,2 & 31,1 \\
DEPB 2,0\%/h (\%) & 69,1 & 54,4 & 47,8 \\
\hline
\end{tabular}

Observou-se que não houve diferença significativa entre os fenos produzidos nas diferentes idades para a degradabilidade ruminal da fibra em detergente neutro (DRFDN) nos tempos de incubação de 0 a 6 horas $(P>0,05)$ (Tabela 8). A partir de 12 horas o feno colhido com 56 dias apresentou maiores DRFDN $(p<0,05)$ em relação aos fenos colhidos nas idades de 84 e 112 dias, que foram semelhantes entre si $(p>0,05)$.

Verifica-se na Tabela 9 que os valores médios da degradabilidade ruminal (fração a, b, c a+b, l) e degradabilidade efetiva da fibra em detergente neutro (DEFDN) foram próximos para os fenos colhidos nas três diferentes idades de crescimento.

Observou-se que não houve diferença significativa entre os fenos produzidos nas diferentes idades para a degradabilidade ruminal da fibra em detergente ácido
(DRFDA) nos tempos de incubação de 0 a 24 horas $(P>0,05)$ (Tabela 10). A partir de 48 horas o feno colhido com 56 dias apresentou maiores DRFDA $(p<0,05)$ em relação aos fenos colhidos nas idades de 84 e 112 dias, que foram semelhantes entre si $(p>0,05)$.

Tabela 8. Desaparecimento ruminal médio (\%) da fibra em detergente neutro dos fenos do capim Andropogon gayanus colhido aos 56, 84 e 112 dias de crescimento. Médias seguidas por letras minúsculas na mesma linha diferem estatisticamente entre si pelo teste SNK $(P<0,05)$. CV (coeficiente de variacão): $5.6 \%$

\begin{tabular}{cccc}
\hline \multirow{2}{*}{$\begin{array}{c}\text { Tempo } \\
\text { (horas) }\end{array}$} & \multicolumn{3}{c}{ Idade de Corte } \\
\cline { 2 - 4 } & $\mathbf{5 6}$ dias & $\mathbf{8 4}$ dias & $\mathbf{1 1 2 ~ d i a s}$ \\
\hline 00 & $11,2^{\mathrm{a}}$ & $12,2^{\mathrm{a}}$ & $11,0^{\mathrm{a}}$ \\
03 & $19,9^{\mathrm{a}}$ & $16,3^{\mathrm{a}}$ & $17,2^{\mathrm{a}}$ \\
06 & $21,2^{\mathrm{a}}$ & $17,1^{\mathrm{a}}$ & $18,2^{\mathrm{a}}$ \\
12 & $37,1^{\mathrm{a}}$ & $30,5^{\mathrm{b}}$ & $28,8^{\mathrm{b}}$ \\
24 & $47,0^{\mathrm{a}}$ & $41,4^{\mathrm{b}}$ & $39,6^{\mathrm{b}}$ \\
48 & $61,7^{\mathrm{a}}$ & $51,7^{\mathrm{b}}$ & $50,6^{\mathrm{c}}$ \\
96 & $72,7^{\mathrm{a}}$ & $63,5^{\mathrm{b}}$ & $62,3^{\mathrm{b}}$ \\
\hline
\end{tabular}

Tabela 9. Valores médios de degradabilidade ruminal e degradabilidade efetiva da fibra em detergente neutro dos fenos do capim Andropogon gayanus colhido aos 56, 84 e 112 dias de idade. Equações geradas pelo modelo Ørskov e McDonald (1979): ${ }^{1} D P=12,5+64,8$ $\left(1-\exp ^{-(0,0383 x t)}\right) ;{ }^{2} D P=13,2+60,4\left(1-\exp ^{-(0,0339 x}\right.$ t) $) ;{ }^{3} D P=12,1+58,1\left(1-\exp ^{-(0,0303 \times t)}\right)$. Legenda: $a=$ fração rapidamente degradável, $b=$ fração potencialmente degradável e $c=$ taxa constante de degradação da fração $b, I$ = fração indegradável $e$ DEFDN $2,0 \% / h$ = degradabilidade efetiva da fibra em detergente neutro nas taxas de passagem ruminal de $2 \% /$ hora.

\begin{tabular}{lccc}
\hline Parâmetros & \multicolumn{3}{c}{ Idade de Corte } \\
\cline { 2 - 4 } & 56 dias & $\mathbf{8 4}$ dias $^{2}$ & 112 dias $^{\mathbf{3}}$ \\
\hline a (\%) & 12,5 & 13,2 & 12,1 \\
b (\%) & 64,8 & 60,4 & 58,1 \\
c (\%/h) & 3,83 & 3,39 & 3,03 \\
a+b (\%) & 77,3 & 73,6 & 70,2 \\
I (\%) & 22,7 & 26,4 & 29,8 \\
DEFDN 2,0\%/h (\%) & 55,1 & 51,2 & 47,1 \\
\hline
\end{tabular}

Verifica-se na Tabela 10 que os valores da fração rapidamente degradável (a) encontrados para os fenos colhidos nas três diferentes idades de crescimento foram próximos, sendo maior para o feno colhido aos 112 dias de idade, seguido respectivamente pelo colhido aos 84 e 56 dias. 
Observa-se na Tabela 11 que os valores da degradabilidade ruminal (fração a, b, c a+b, I) e da degradabilidade efetiva da fibra em detergente ácido (DEFDA) foram próximos para os fenos colhidos nas três diferentes idades de crescimento.

Tabela 10. Desaparecimento ruminal médio (\%) da fibra em detergente ácido dos fenos do capim Andropogon gayanus colhido aos 56, 84 e 112 dias de crescimento. Médias seguidas por letras minúsculas na mesma linha diferem estatisticamente entre si pelo teste SNK $(P<0,05)$. CV (coeficiente de variação): $5,1 \%$

\begin{tabular}{cccc}
\hline \multirow{2}{*}{$\begin{array}{c}\text { Tempo } \\
\text { (horas) }\end{array}$} & \multicolumn{3}{c}{ Idade de Corte } \\
\cline { 2 - 4 } & $\mathbf{5 6}$ dias & $\mathbf{8 4}$ dias & $\mathbf{1 1 2}$ dias \\
\hline 00 & $13,9^{\mathrm{a}}$ & $14,7^{\mathrm{a}}$ & $15,8^{\mathrm{a}}$ \\
03 & $18,5^{\mathrm{a}}$ & $20,4^{\mathrm{a}}$ & $21,9^{\mathrm{a}}$ \\
06 & $20,5^{\mathrm{a}}$ & $21,7^{\mathrm{a}}$ & $22,8^{\mathrm{a}}$ \\
12 & $31,1^{\mathrm{a}}$ & $30,3^{\mathrm{a}}$ & $29,9^{\mathrm{a}}$ \\
24 & $42,1^{\mathrm{a}}$ & $40,0^{\mathrm{a}}$ & $39,6^{\mathrm{a}}$ \\
48 & $56,6^{\mathrm{a}}$ & $50,6^{\mathrm{b}}$ & $49,5^{\mathrm{b}}$ \\
96 & $70,0^{\mathrm{a}}$ & $61,6^{\mathrm{b}}$ & $60,9^{\mathrm{b}}$ \\
\hline
\end{tabular}

Tabela 11. Valores médios de degradabilidade ruminal e degradabilidade efetiva da fibra em detergente ácido dos fenos do capim Andropogon gayanus colhido aos 56, 84 e 112 dias de idade. Equações geradas pelo modelo Ørskov e McDonald (1979): ${ }^{1} D P=15,2+59,4$ $(1-\exp -(0,0371 x t)) ;{ }^{2} D P=16,3+52,1(1-\exp -(0,0322 x$ t)); ${ }^{3} D P=16,7+50,3(1-\exp -(0,0291 \times t))$. Legenda: $a=$ fração rapidamente degradável, $b=$ fração potencialmente degradável e $c=$ taxa constante de degradação da fração $b, I$ = fração indegradável $e$ DEFDA $2,0 \% / h$ = degradabilidade efetiva da fibra em detergente ácido nas taxas de passagem ruminal de 2\%/hora.

\begin{tabular}{lccc}
\hline Parâmetros & \multicolumn{3}{c}{ Idade de Corte } \\
\cline { 2 - 4 } & 56 dias & $\mathbf{8 4}$ dias $^{\mathbf{2}}$ & $\mathbf{1 1 2}$ dias $^{\mathbf{3}}$ \\
\hline a (\%) & 15,2 & 16,3 & 16,7 \\
b (\%) & 59,4 & 52,1 & 50,3 \\
c (\%/h) & 3,71 & 3,22 & 2,91 \\
a+b (\%) & 74,6 & 68,4 & 67,0 \\
I (\%) & 25,4 & 31,6 & 33,0 \\
DEFDA 2,0\%/h (\%) & 53,8 & 48,4 & 46,5 \\
\hline
\end{tabular}

\section{DISCUSSÃO}

Observou-se que no período inicial de incubação ruminal de 0 e 3 horas (Tabela 2), os fenos colhidos nas três diferentes idades (56, 84 e 112 dias) apresentaram valores semelhantes $(p>0,05)$ de desaparecimento ruminal da matéria seca (DRMS). É provável que a maior parte do DRMS neste tempo deva - se ao escape de pequenas partículas dos fenos pelos poros dos sacos de incubação.

A DRMS tende a ocorrer em menor proporção nos tempos iniciais de incubação ruminal uma vez que estes materiais são ricos em fibras $(71,10,73,62$ e $75,54 \%$ de FDN nas idades de 56,84 e 112 dias respectivamente) conforme observado na Tabela 1. Segundo Jung e Allen (1995) para que haja degradação ruminal das porções fibrosas é necessário que os microorganismos ruminais (principalmente bactérias) estejam aderidos às partículas do alimento, o que demanda tempo para ocorrer. Dessa forma, ao avaliarmos forrageiras, maiores proporções e diferenças nas taxas de degradação ruminal tendem a ser encontrados no avançar do tempo de incubação in situ.

Rodrigues (2004) avaliando a degradabilidade ruminal do capim Andropogon gayanus colhido aos 63 dias de crescimento encontrou $72,2 \%$ de DRMS para o tempo de incubação ruminal de 96 horas, valor este bastante próximo ao encontrado no feno colhido aos 56 dias do presente trabalho.

Observa-se na Tabela 3 que os valores da fração a encontrados para os fenos colhidos nas três diferentes idades de crescimento foram próximos, sendo maior para o feno colhido aos 112 dias de idade, seguido respectivamente pelo colhido aos 84 e 56 dias. É possível que estes resultados sejam influenciados ao escape de pequenas partículas dos fenos pelos poros dos sacos de incubação no tempo zero (Tabela 2).

Com relação à fração potencialmente degradável (b), verifica - se que esta foi maior para o feno colhido aos 56 dias de idade em relação as outras duas idades. Observa - se também que a fração (b) do feno colhido aos 84 dias foi superior ao colhido aos 112 dias de idade, o que vem a demonstrar que fenos produzidos com plantas mais jovens tendem a possuir maior proporção de MS degradada pela fermentação ruminal. Resultados próximos ao deste trabalho foram encontrados por Moreira et al. (2013) avaliando feno de $A$. gayanus colhido em 4 diferentes idades entre elas também 56, 84 e 112 dias (sendo os respectivos valores para estas idades de $18,9 \%, 20,0 \%$ e $20,9 \%$ fração a e de $56,8 \%, 52,9 \%$ e $49,2 \%$ - fração $b$ ) e por Lacerda et al. (2009) trabalhando com esta forrageira verde colhida aos 35 e 63 dias de crescimento, onde encontrou - se valores para a fração a de $18,78 \%$ e $20,28 \%$ e de $57,25 \%$ e $54,28 \%$ para a fração $b$ respectivamente.

Quanto a taxa constante de degradação da matéria seca (c) foi verificado maior taxa de degradação para o feno colhido aos 56 dias, e a menor taxa sendo registrada para o colhido aos 112 dias (Tabela 3). Fato este lógico, uma vez que, taxas de degradação tendem a reduzir com o avançar da idade da forrageira devido ao aumento de constituintes de mais difícil degradação e dos indegradavéis, sendo estes representados respectivamente em sua maioria pelas porções fibrosas e pela lignina. Esses compostos tendem a aumentar a 
partir do desenvolvimento da parede celular secundária das forrageiras, sendo essa a responsável por conferir maior rigidez às plantas na medida que envelhecem (Cavalcanti et al., 2018; 2019).

Os valores de $c$ encontrados neste trabalho variaram de 3,10 a $4,20 \% / h$, estando superiores aos encontrados por Ribeiro Júnior et al. (2014) trabalhando com silagens de capim $A$. gayanus colhido nas idades de 56,84 e 112 dias que encontraram valores de $c$ variando de 2,4 a 3,1\%/h. Já Moreira et al. (2013) avaliando fenos de $A$. gayanus colhidos em 4 diferentes idades encontraram valores de $c$ próximos ao deste trabalho (3,5 a 4,2\%/h.).

É importante ressaltar que os valores de $c$ encontrados nesse trabalho estão dentro do intervalo observado por Sampaio (1992) em fenos de gramíneas tropicais, onde encontrou valores variando de 5,0 a 3,0\%/h.

Segundo Sampaio (1992), as forragens mais digestíveis apresentam valores mais altos da fração potencialmente degradável $(a+b)$, que necessitam também de mais altos valores de taxa de degradação (c), para alcançarem o potencial máximo de degradação em menor tempo (fato este evidenciado na Tabela 3). Para este autor, o potencial máximo de degradação e a taxa de degradação são os principais parâmetros na qualificação de uma forragem. Um elevado valor de $a+b$ indica um material muito degradável, ao passo que um maior valor de $c$ implica em menor tempo para o desaparecimento da fração potencialmente degradável, sendo que forragens de boa qualidade devem apresentar taxas de degradação superiores a $2 \% / h$.

A degradabilidade efetiva da matéria seca (DEMS) calculada para a taxa de passagem de $2,0 \% / \mathrm{h}$ foi superior para o tratamento com o feno colhido aos 56 dias de idade $(57,5 \%)$, seguido pelas idades de 84 e 112 dias (com valores de 54,3 e $51,7 \%$ respectivamente).

Os valores obtidos para DEMS, a uma taxa de passagem de $2 \% /$ hora (taxa esta recomendada para a avaliação de forrageiras) apresentaram valores condizentes com os encontrados por Cavalcanti et al. (2016) trabalhando com estes mesmos materiais em experimento de consumo e digestibilidade aparente. $\mathrm{O}$ autor encontrou valores de digestibilidade aparente da matéria seca (DAMS) de 60,7\%, 54,7\% e 45,6\% para as idades de 56, 84 e 112 dias respectivamente, estando bem próximos aos encontrados neste trabalho para a DEMS. Moreira et al. (2013) também encontraram valores próximos para a DEMS, os valores variaram de 55,9 a $52,2 \%$.

Quando os valores DEMS dos fenos avaliados são comparados com os valores de digestibilidade in vitro (DIVMS), presentes na Tabela 1, observa-se que estão próximos em todas as idades avaliadas.

A redução da degradabilidade da $\mathrm{MS}$ em função da idade tem sido relatada em vários trabalhos na literatura. Essa redução da degradabilidade da MS com a maturidade da planta pode ser explicada pelo aumento da relação haste/folha e declínio da qualidade dos componentes da haste. As hastes apresentam em sua composição tecidos vegetais de menor taxa de degradação ruminal (esclerênquima e xilema). Estes são tecidos vegetais de sustentação e vasculares, que possuem células densamente agrupadas com paredes espessas e lignificadas, de difícil degradação pelos microrganismos ruminais (Jung \& Allen, 1995).

Observou-se que no período inicial de incubação ruminal de 0 e 3 horas (Tabela 4), os fenos colhidos nas três diferentes idades (56, 84 e 112 dias) apresentam valores semelhantes $(p>0,05)$ de desaparecimento ruminal da matéria orgânica (DRMO). A semelhança encontrada para a DRMO dos fenos nos tempos iniciais de incubação também podem ser explicados pelos mesmos motivos encontrados para a DRMS neste período.

Verificou - se que os parâmetros de DRMO, apresentados na Tabela 4, seguiram comportamento semelhante ao descrito para a DRMS (Tabela 2), possivelmente isto se deva a uma possível correlação existente entre estas duas variáveis, fato evidenciado no trabalho de Ribeiro Júnior et al. (2014).

Observou-se na Tabela 5 que os valores da fração $a$ encontrados para os fenos colhidos nas três diferentes idades de crescimento foram próximos, sendo maior para o feno colhido aos 112 dias de idade, seguido respectivamente pelo colhido aos 84 e 56 dias. É possível que estes resultados sejam influenciados ao escape de pequenas partículas dos fenos pelos poros dos sacos de incubação no tempo zero (Tabela 4).

Com relação à fração potencialmente degradável (b), verificou - se que esta foi maior para o feno colhido aos 56 dias de idade em relação as outras duas idades. Observa - se também que a fração (b) do feno colhido aos 84 dias foi superior ao colhido aos 112 dias de idade, o que vem a demonstrar que fenos produzidos com plantas mais jovens tendem a possuir maior proporção de MO degradada pela fermentação ruminal. Estas taxas estão próximas as encontradas por Sousa et al. (2011) que avaliando Brachiaria brizantha em diferentes épocas do ano por meio da técnica in situ encontraram taxas constantes de degradação da matéria orgânica (c) variando de 3,60 a 2,23\%/hora.

Quanto as frações indegradáveis, estas apresentaram o menor valor $(24,9 \%)$, com o feno colhido aos 56 dias de crescimento, seguido pelos colhidos aos 84 e 112 dias respectivamente.

Para os valores referentes à degradabilidade efetiva da matéria orgânica (DEMO) ocorreu uma redução com o avançar da idade de corte, podendo estar relacionada à menor taxa de degradação ocasionada pelas características de senescência das forrageiras (Tabela $5)$.

A DEMO calculadas para a taxa de passagem de $2,0 \% / h$ para fenos de capim $A$. gayanus colhido aos 56 , 84 e 112 dias foram superiores às observadas por Ribeiro Júnior et al. (2014) trabalhando com silagens deste capim colhido nas mesmas idades deste trabalho. É possível que a menor degradabilidade das silagens de capim $A$. gayanus em comparação aos fenos esteja relacionada a degradação de nutrientes (carboidratos solúveis e parte das hemiceluloses) durante o processo de fermentação da silagem.

O desaparecimento ruminal da proteína bruta (DRPB) foi maior $(p<0,05)$ para o feno colhido aos 56 dias de crescimento em comparação aos colhidos com 84 e 
112 dias, que foram semelhantes entre si $(p>0,05)$, exceto nos tempos de 24 e 48 horas (Tabela 6). A maior DRPB encontrada em forrageiras mais jovens pode estar relacionada à maior participação de fontes de nitrogênio não proteíco e de proteínas de maior solubilidade.

Castro et al. (2007) encontraram valores da DRPB para a silagem de capim Tanzânia obtida a partir da idade de corte de 43 dias nos tempos de incubação de 6 horas $(50,5 \%), 12$ horas $(58,2 \%)$ e 24 horas $(63,9 \%)$, estando próximos aos encontrados neste trabalho para o feno colhido aos 56 dias nos mesmos tempos de incubação (Tabela 6). Estes mesmos autores encontraram valores da DRPB no tempo de incubação de 96 horas variando de 76,6 a 54,9\%, ocorrendo redução desta variável com o avançar da idade da forrageira, como evidenciado em nosso trabalho.

A degradação da proteína no rúmen pode ser afetada por vários fatores, como a composição química e física da proteína bruta (relação entre nitrogênio não protéico e proteína verdadeira, a estrutura tridimensional da molécula de proteína e a presença de ligações dissulfeto), a atividade proteolítica microbiana, o acesso microbiano à proteína, o tempo de retenção do alimento no rúmen, o pH ruminal, o processamento do alimento e a temperatura ambiente Jung (2011).

Segundo Jung (2011) a fração de nitrogênio ligado à fibra insolúvel em detergente ácido (NIDA) consiste de compostos nitrogenados associados a lignina, taninos, produtos da reação de Maillard, sendo estes resistentes a ação das enzimas microbianas e intestinais. Essa fração pode aumentar com o avançar da idade de corte da planta, com o tipo de forrageira, e com as condições ambientais durante o desenvolvimento da forrageira, proporcionando diferentes valores da DRPB, fato encontrado neste trabalho.

A fração rapidamente degradável da proteína bruta (a) foi maior para o feno colhido aos 56 dias de crescimento, seguido pelos colhidos aos 84 e 112 dias que apresentaram valores bem próximos entre si (Tabela 7). As folhas são as partes da planta que apresentam mais rápida degradação, concentrando grande parte de sua proteína. Seguramente o valor encontrado para o feno colhido aos 56 dias deva - se ao fato deste material apresentar uma maior relação folha: colmo em comparação aos outros fenos, o que é esperado uma vez que a medida que as forrageiras envelhecem reduzem o peso das folhas em relação ao dos colmos. Além disso, a maior proporção colmo: folha encontrada em forrageiras mais velhas, faz com que plantas fenadas passem por maior tempo de secagem até alcançarem ponto de feno, requerendo assim um maior revolvimento. Isso faz com que uma maior quantidade de folhas possam ser perdidas durante 0 processo de fenação, reduzindo, consequentemente, a proporção de $\mathrm{PB}$ originária das folhas, levado a um impacto direto sobre este parâmetro.

Observou-se que a fração potencialmente degradável da proteína bruta (b) variou de $52,2 \%$ a $46,4 \%$, ocorrendo redução com o avançar da idade de corte (Tabela 7), sendo este fenômeno relacionado ao aumento da proporção de nitrogênio ligado às frações fibrosas na forma de NIDN e NIDA (Tabela 2). As interações entre proteína e lignina podem aumentar com o avançar da idade de corte, ocasionando uma redução na fração (b) e na (a).

A DEPB calculadas para a taxa de passagem de $2,0 \% / h$ para os fenos de capim $A$. gayanus colhido aos 56,84 e 112 dias foram superiores às observadas por Ribeiro Júnior et al. (2014) trabalhando com silagens deste capim colhido nas mesmas idades deste trabalho, encontrando valores variando de $40,1 \%$ a $28,7 \%$.

Quando se analisa a taxa de passagem de $2 \% /$ hora, que é a esperada para ruminantes consumindo apenas volumosos observou-se que estes valores são superiores aos reportados por Cavalcanti et al. (2016) para a digestibilidade aparente da proteína bruta (DAPB) deste mesmo material em carneiros, que foi de $55,69 \%, 41,10 \%$ e $26,99 \%$ para os fenos obtidos com as plantas nas idades de 56, 84 e 112 dias de crescimento.

Deve - se levar em consideração o fato de que o experimento de Cavalcanti et al. (2016) foi baseado na DAPB, sendo esta calculada pela diferença da quantidade de PB do material consumido e da excretada nas fezes dos animais. Porém, a PB presente nas fezes dos animais não é composta apenas da proteína digestível dos alimentos, também estão presentes proteínas de origem endógena, proveniente das secreções e descamações celulares do trato digestivo dos animais. Por isso os valores de DAPB são menores que os encontrados para a DEPB na técnica de avaliação de alimentos pela incubação in situ. A mensuração da DRPB, e a inferência da DEPB, é uma vantagem que a técnica de incubação in situ apresenta sobre a técnica in vivo na mensuração do aproveitamento da PB por parte dos ruminantes Rodrigues et al. (2011).

Segundo Jung (2011) à medida que a planta atinge maturidade ocorre incremento na síntese de polímeros estruturais depositados nas células vegetais, principalmente lignina, interferindo negativamente na DRFDN, fato este que pode estar relacionado ao atual trabalho.

A perda de FDN no tempo zero seguramente deve - se ao escape de pequenas partículas através dos poros dos sacos de incubação, uma vez que porções fibrosas não são prontamente solubilizadas, configurando - se em um dos problemas da técnica in situ quando são avaliadas porções fibrosas em forrageiras.

Para que a fibra seja degradada no ambiente ruminal há a necessidade de que a microbiota presente tenha se aderido às suas partículas, sendo a diferença da DRFDN somente percebida a partir do tempo de 12 horas.

A fração fibrosa insolúvel em detergente neutro é constituída por polímeros de hemiceluloses, celulose e lignina. Após a colonização dessa fração pelos microorganismos ruminais, será degradada a fração potencialmente digestível (constituída por hemiceluloses e celulose digestíveis). Já no resíduo indigestível desta fração espera-se encontrar partes das hemiceluloses e da celulose que estejam intimamente associadas à lignina, além da lignina isolada. Com o avanço do estádio de maturação (idade de corte) ocorreu aumento do resíduo indigestível da 
fração fibrosa insolúvel em detergente neutro, o que contribui para a redução da degradabilidade ruminal da fibra em detergente neutro.

Observou-se na Tabela 9 que os valores da fração rapidamente degradavél (a) encontrados para os fenos colhidos nas três diferentes idades de crescimento foram próximos, sendo maior para o feno colhido aos 84 dias de idade, seguido respectivamente pelo colhido aos 56 e 112 dias. É possível que estes resultados sejam influenciados pelo escape de pequenas partículas dos fenos pelos poros dos sacos de incubação no tempo zero (Tabela 8).

Observou-se que a fração potencialmente degradável da fibra em detergente neutro (b) variou de $64,1 \%$ a $58,1 \%$, ocorrendo redução com o avançar da idade de corte (Tabela 9).

Resultados próximos ao deste trabalho foram encontrados por Moreira et al. (2013) avaliando feno de A. gayanus colhido em 4 diferentes idades entre elas as de $56,84,112$ dias, sendo os respectivos valores para estas idades de $11,5 \%, 12,2 \%$ e $12,7 \%$ - fração a e de $64,1 \%, 60,2 \%$ e $57,0 \%$ - fração $b$.

Quanto a taxa constante de degradação da fibra em detergente neutro (c) foi verificado maior taxa de degradação para o feno referente à idade de 56 dias $(3,83 \% / \mathrm{h})$, e a menor taxa sendo registrada para o feno colhido aos 112 dias (3,03\%/h) (Tabela 9).

Os valores de $c$ encontrados foram superiores aos encontrados por Ribeiro Júnior et al. (2014) trabalhando com silagens de capim $A$. gayanus colhido nas idades de 56, 84 e 112 dias que encontrou valores de $c$ variando de $2,32 \%$ a $1,04 \% / h$.

Resultados próximos aos deste trabalho foram encontrados por Moreira et al. (2013) onde encontraram valores de $c$ variando de $4,0 \%$ a $3,4 \% / h$ e por Sousa et al. (2011) trabalhando com Brachiaria brizantha colhida em pastagens em várias épocas do ano que encontraram taxas de degradação da fração lentamente degradável variando de 3,42\% a 2,80\%/hora.

A degradabilidade efetiva da fibra em detergente neutro (DEFDN) calculada para a taxa de passagem de $2,0 \% / \mathrm{h}$ foi superior para o tratamento com o feno colhido aos 56 dias de idade $(55,1 \%)$, seguido pelas idades de 84 e 112 dias (com valores de 51,2\% e $47,1 \%$ respectivamente).

Moreira et al. (2013) avaliando o feno de $A$. gayanus colhido em 4 diferentes idades encontraram valores para a DEFDA, a uma taxa de passagem de $2 \% /$ hora de $52,1,52,2$ e 48,1\% para as respectivas idades de 56, 84 e 112 dias, estando estes bem próximos aos encontrados em nosso trabalho.

Ao analisar as taxas de passagem a $2 \% /$ hora pode-se perceber que estes valores são menores que os encontrados por Cavalcanti et al. (2016) para a digestibilidade aparente da fibra em detergente neutro (DAFDN) em carneiros, onde encontrou valores de $63,27,59,97$ e $51,00 \%$, para os fenos colhidos com este mesmo material nas idades de 56, 84 e 112 dias respectivamente. As menores DEFDN encontradas em relação as DAFDN podem ser ocasionadas devido ao fato de que alimentos incubados no rúmen não sofrem processos de mastigação e ruminação, processos estes que tendem em aumentar a degradação da porção fibrosa dos alimentos Rodrigues et al. (2011).

A perda de FDA no tempo zero não reflete a perda por solubilidade, uma vez que esta fração não é solubilizada no ambiente ruminal, sendo representada apenas pela perda de pequenas partículas pelos poros dos sacos de incubação.

A fração fibrosa insolúvel em detergente ácido é constituída por celulose e lignina. O resíduo digestível no rúmen dessa fração que é solubilizado em detergente ácido é constituído principalmente pelas hemiceluloses. Dessa forma pode ser que a diferença na significância do desaparecimento da FDA do feno colhido aos 56 dias, em comparação àqueles colhidos aos 84 e 112 dias, deva - se a maior degradabilidade apresentada pelas hemiceluloses do feno colhido nesta idade. As hemiceluloses são as frações da fibra que apresentam variações em sua digestibilidade a medida que ocorre aumento na maturidade das plantas. Com a maturação aumentam - se as ligações covalentes da lignina com as hemiceluloses, tornando-as indisponíveis para a degradação microbiana (Jung, 2011).

Observou-se na Tabela 10 que os valores da fração rapidamente degradável (a) encontrados para os fenos colhidos nas três diferentes idades de crescimento foram próximos, sendo maior para o feno colhido aos 112 dias de idade, seguido respectivamente pelo colhido aos 84 e 56 dias. É possível que estes resultados sejam influenciados ao escape de pequenas partículas dos fenos pelos poros dos sacos de incubação no tempo zero.

Resultados próximos ao deste trabalho foram encontrados por Moreira et al. (2013) avaliando feno de A. gayanus colhido em 4 diferentes idades, sendo os respectivos valores para estas idades de 58,8, 54,1 e $50,8 \%$ - fração $b$.

Resultados próximos aos deste trabalho foram encontrados por Moreira et al. (2013) avaliando feno de A. gayanus colhido em 4 diferentes idades, onde encontraram valores de $c$ variando de 3,9 a $3,1 \% / h$ e por Ribeiro Júnior et al. (2014) trabalhando com silagens de capim $A$. gayanus que encontraram valores de $c$ variando de 3,4 a $2,3 \% / h$.

A degradabilidade efetiva da fibra em detergente neutro (DEFDA) calculada para a taxa de passagem de 2,0\%/h foi superior para o tratamento com o feno colhido aos 56 dias de idade $(53,8 \%)$, seguido pelas idades de 84 e 112 dias (com valores de 48,4 e $46,5 \%$ respectivamente).

Moreira et al. (2013) encontraram valores para a DEFDA, a uma taxa de passagem de $2 \%$ /hora de 55,6 , 56,2 e $52,7 \%$ para as respectivas idades de 56,84 e 112 dias, sendo estes superiores aos encontrados em nosso trabalho.

Ao analisar as taxas de passagem a $2 \%$ /hora pode-se perceber que estes valores são menores que os encontrados por Cavalcanti et al. (2016) para a digestibilidade aparente da fibra em detergente ácido (DAFDA) em carneiros, onde encontrou valores de $59,17,55,45$ e $47,91 \%$, para os fenos colhidos com este mesmo material nas idades de 56, 84 e 112 dias respectivamente. 
Percebe - se que os resultados obtidos para a degradabilidade efetiva a uma taxa de passagem de $2 \%$ /hora das frações fibrosas (FDN e FDA), são discordantes quando comparados com os valores encontrados no experimento in vivo conduzido por Cavalcanti et al. (2016) utilizando estes mesmos materiais. O que pode ser explicado devido a ausência do processo de mastigação e ruminação e as perdas de materiais fibrosos (FDN e FDA), no escape de pequenas partículas através dos poros dos sacos de incubação, sendo considerados no experimento in situ como totalmente degradáveis, quando na verdade não o são.

\section{CONCLUSÕES}

Os resultados da cinética de degradação ruminal da MS, MO, PB, FDN e FDA dos fenos de capim Andropogon gayanus indicam que a planta colhida aos 56 dias apresenta melhor valor nutricional.

\section{REFERÊNCIAS}

Castro, G. H. F.; Graça, D. S. \& Gonçalves, L. C. 2007. Cinética de degradação e fermentação ruminal da Brachiaria brizantha cv. Marandu colhida em diferentes idades ao corte. Arquivo Brasileiro de Medicina Veterinária e Zootecnia, 59:1538-1544.

Cavalcanti, A.C.; Saliba, E.O.S.; Couto Filho, C.C.C.; Silva, F.A.; Silva, C.M.R. \& Macedo, T.M. 2019. Partição da energia e produção de metano em ovinos alimentados com feno de Andropogon Gayanus colhido em três diferentes idades. Revista de la Facultad de Agronomía La Plata.118(1):93-104.

Cavalcanti, A.C.; Saliba, E.O.S.; Couto Filho, C.C.C.; Silva, F.A.; \& Silva, C.M.R. 2018. Avaliação de fenos produzidos com Andropogon gayanus em diferentes idades empregando-se a técnica in vitro semiautomática de produção de gases. Revista de la Facultad de Agronomía, La Plata.117(2):285-291.

Cavalcanti, A.C.; Saliba, E.O.S.; Gonçalves, L.C.; Rodriguez, N.M.; Borges, I.; \& Borges, A.L.C.C. 2016. Consumo e digestibilidade aparente do feno de Andropogon gayanus colhido em três idades diferentes. Ciencia Animal Brasileira, Goiânia, 17(4):482-490.

Detmann, E., Souza, M.A.; \& Valadares Filho, S.C. 2012. Métodos para análise de alimentos. Visconde do Rio Branco: Universidade Federal de Viçosa. 1:214. Euclydes, R.F. 2005. Sistema para análises estatísticas (SAEG 9.0). Viçosa: Funarbe.
Jung, H. J. G.; \& Allen, M. S. 1995. Characteristics of plant cell wall affecting intake and digestibility of forages by ruminants. Journal of Animal Science. 73:2774-2790. Jung, H. J. G. 2011.Forage digestibility: the intersection of cell wall lignifications and plant tissueanatomy. In: III Simpósio Internacional Avanços em Técnicas de Pesquisa em Nutrição de Ruminantes. USP, Pirassununga, SP.

Lacerda, M.S.B; Alves, A.A.; Oliveira, M.E.; Rogério, M.C.P.; Carvalho, T.B.; \& Veras, V.S. 2009.Composição bromatológica e produtividade do capim Andropogon em diferentes idades de rebrota em sistemas silvipastoril. Acta Scientiarum. Animal Sciences. 31(2):123-129.

Moreira, G. R.; Saliba, E.O. S ; Gonçalves, L. C.; Mauricio, R. M. ; SOUSA, L. F.; Rodriguez, N. M. ; \& Lana, A. M. Q. 2013. Avaliação nutricional de fenos produzidos com Andropogon gayanus cv. Planaltina. Arquivo Brasileiro de Medicina Veterinária e Zootecnia. 65:865-873.

Ørskov, E. R.; \& McDonald, I. 1979. The estimation of protein degradability in the rumen from incubation measurements weighted according to rate of passage. Journal Agriculture Science. 92(2): 499-503.

Ribeiro Júnior, G.O.; Velasco, F.O.; Faria Junior; W.G.; Teixeira, A.M.; Machado, F.S.Magalhàes, F.A.; Jayme, D,G.; \& Gonçalves, L.C. 2014. Cinética de degradação in situ das silagens de capim Andropogon gayanus produzidas em três idades de corte. Arquivo Brasileiro de Medicina Veterinária e Zootecnia. 66(6):1883-1890.

Rodrigues, A.L.P. 2004. Degradabilidade in situ da matéria seca de forrageiras tropicais obtidas em diferentes épocas de corte. Arquivo Brasileiro de Medicina Veterinária e Zootecnia. 566(5):658-664.

Rodrigues, M.T, Vieira, R.A.M. In: Berchielli, T.T.; Pires, A.V.; \& Oliveira, S.G. 2011. Metodologias aplicadas ao fracionamento de alimentos. Nutrição de Ruminantes. Jaboticabal: Funep. 2:25-55.

Sampaio, I. B. M. 1992. Avaliação do efeito do tratamento químico com hidróxido de rádio sobre a digestibilidade de gramíneas tropicais fenadas. In: REUNIÃO ANUAL DA SOCIEDADE BRASILEIRA DE ZOOTECNIA. 29, 1992, Lavras, Anais... Lavras: RBZ. $1: 161$.

Sousa, L.F. Mauricio, R.M.; Gonçalves, L.C.; Borges, I.; Moreira, G.R. 2011. Cinética de fermentação ruminal in vitro da forrageira Brachiaria brizantha cv. Marandu em sistema silvipastoril. Arquivo Braileiro de Medicina Veterinária e Zootecnia. 63(2):382-391. 